Original Research Paper

\title{
Structural Equation Model (SEM) for Evaluating Factors Affecting ICT4D Project Success
}

\author{
${ }^{1}$ Houda Fakhkhari, ${ }^{1}$ Bouchaib Bounabat and ${ }^{2}$ Maria Bennani \\ ${ }^{1}$ ALQUALSADI Team, Rabat Information Technology Center, ENSIAS, Mohammed V University, Rabat Morocco \\ ${ }^{2}$ Lalla Salma Foundation - Cancer Prevention and Treatment, Rabat, Morocco
}

\section{Article history}

Received: 15-04-2021

Revised: 19-06-2021

Accepted: 03-08-2021

Corresponding Author:

Houda Fakhkhari

ALQUALSADI Team, Rabat

Information Technology

Center, ENSIAS, Mohammed

V University, Rabat Morocco

Email: houda_fakhkhari@um5.ac.ma

\begin{abstract}
Information Communication Technology for Development (ICT4D) enables organizations to transform and evolve. Despite the contributions of methodologies and models for project management, the number of failed ICT4D projects remain high; as a consequence, researching crucial success factors of ICT4D projects remains an important matter for practitioners and researchers. Studies and researches on factors impacting ICT4D projects' success are various, fragmented and have used different methods to explore the relatedness between various variables. Structural Equation Modeling approach (SEM) has attracted very little attention in the definition of critical factors affecting ICT and ICT4D projects' success. From this standpoint, we as author of this study have applied the SEM approach and built an empirical model that identifies and justifies the topmost factors that impact the best outcome of ICT initiatives and projects conducted for development. In this regard, we reviewed relevant literature to compile and synthesize important success factors in ICT4D projects. The results obtained revealed that there isn't an agreement on ICT4D project factor success. Our work consisted of consolidating the ICT4D success factors and developing a quantitative approach using smart-PLS version 3.3.3 to test and verify the proposed conceptual model. Particularly, we undertook this study to highlights the correlation between "Leadership and Governance", "Project Management", "Quality Management" and "Foundations and Requirements" factors and how these correlated to the outcomes of the ICT4D project. The results indicate that the R Square value of the model attained 0.84 which reveals that the latent constructs previously mentioned justified $84 \%$ of the variance in project success. This study lays out the contours of the existing literature concluding the critical success factors and coming up with a framework for decision-makers, researchers, practitioners and organizations intending to initiate and implement an ICT4D project.
\end{abstract}

Keywords: ICT4D, Success Factors, Structural Equation Modeling Approach (SEM), Smart PLS

\section{Introduction}

Information Communication Technology for Development refers to the manipulation, adoption and/or diffusion of ICT tools that enhance peoples' lives by improving their economic, social and human conditions in their respective culture, or country (Qureshi, 2019). Many countries, both developed and developing, have initiated and implemented ICT4D initiatives to transform and ameliorate their citizens' lives. However, despite the efforts deployed and the contributions of methodologies and models for project management, the number of failed ICT4D projects worldwide remain high (Gunawong and Gao, 2017; Iriarte and Bayona, 2020; Seo et al., 2018).

For instance, in 2011, Morocco drew up its e-Government program and broke it down into 89 projects intended for administrative and public services. The objective sought was to bring up the UN index to 0.8 by the end of 2013 (Ministry of Industry, 2011).

In September 2014, the "Court of account": An institution created to control the regularity of the state's public accounts, published its review on the evaluation of the "Maroc Numeric 2013" plan. This report revealed the slow progress of the strategy and the non-realization of 
many priority and structuring projects. For e-Government projects only $36 \%$ of projects were operational and $3 \%$ in progress, while $38 \%$ of programmed projects were late or problematic while $22 \%$ of the projects had not started. This was due to several dysfunctions, among which, deficiencies in the establishment of the strategy, inappropriate governance model and an ineffective management process (Cours des comptes, 2014). Another assessment endeavor of online public services was conducted and published by the " Court of account" in May 2019 (Cours des comptes, 2019) had concluded the same outcomes.

Besides, in June 2019, the Ministry of administration and public service reform had performed an evaluation of online public services maturity using the e-readiness index. This analysis considered 453 online services proposed by 87 administrations and public organizations. $86 \%$ were business services and $14 \%$ were support services. According to this analysis, the online maturity level of these services was insufficient: The e-readiness score calculated was $48 \%$, indeed only $23 \%$ of studied services were completely dematerialized of which $43 \%$ were complementary services which had a very limited effect in improving the rendering of services provided to citizens (Ministry of Economy, 2019). Moreover, in 2020 Morocco regressed in the United Nations (UN) ranking to 106th position (82nd in 2014) in the egovernment index for a value of 0.529 which was far from the objective of 0.8 planned by the "Maroc numeric 2013" plan (Nations United, 2020).

Project performance is widely considered and adopted in general IT project success field. Those researches, works and investigations have enriched our understanding of project success. Therefore, it is required to examine the foremost success factors within the framework of ICT4D projects, given their significant contribution in the enhancement of citizens' life and their high rate of failure and their complexity. There are few studies that comprehensively summarize the ICT4D key success factors while there are a notable number of studies about ICT project success.

The overall goal of this study is to broaden current knowledge of ICT4D projects and to study the critical factors that effectively influence and impact those projects' success by conducting a systematic literature review, building a conceptual model by using smart-PLS version 3.3.3 while considering the factors identified in the literature review as exogenous latent constructs and ICT4D initiative success as the endogenous latent variable. Based on previous studies (Abdulla, 2015; Dijkers et al., 2018; Kaur et al., 2020; Walton and Heeks, 2011) ICT4D initiatives and projects are facing many problems and challenges. Studies in this field have indicated some key factors, namely governance practices, top management involvement, agility, stakeholders' commitment, project management methodologies, end-user's involvement and many other factors have a profound effect on the success of ICT4D projects. However, to our knowledge, no works have been putting forward with an empirical model that demonstrates how these exogenous variables affect the ICT4D initiatives' success and which variables is the most decisive in influencing the ICT4D initiatives success.

This study is a chapter of the ICT4D studies area that will extend the knowledge in the ICT4D's field by providing a theoretical framework and approaches for developing, implementing and sustaining ICT4D initiatives. A first step towards implementing an efficient, effective and sustain ICT4D initiative would be to identify practices and factors that impact and affect the performance and outcomes of these initiatives. Consequently, our initiative seeks to discover, compile and synthesize the critical practices and factors and to propose an overarching framework that would allow researchers and practitioners to elaborate and implement an ICT4D strategy.

The target of this study are researchers who are seeking for a comprehensive investigation of the crucial variables affecting and impacting the ICT4D project's success coupled with practitioners who are implicated in the ICT4D field and would like to find frameworks for developing, implementing, assessing and monitoring ICT4D projects.

This study is presented as follows: Literature review and the study selection are outlined in section two, the empirical model is described in section three, data analysis of this review along with discussion on the outputs of this approach are detailed in section four and the proposed ICT4D project cycle is displayed in section five. Finally, the conclusion of this study is spelled out in section six.

\section{Literature Review and Study Selection}

\section{Database search}

For this research, the authors conducted a literature review based on scientific databases providing the foremost and the highest impact full-text journals and conference proceedings, covering the fields of ICT4D, such as Science Direct (Elsevier), Springer Link, google scholar and ACM Digital Library.

The following search keywords are used to find relevant studies in the paper's title, keywords and abstract: "ICT Project success" OR "ICT Project failure" OR "ICT project management" OR "ICT4D Project success" OR "ICT4D Project failures" OR "ICT4D Implementation" OR "ICT4D Framework" OR "ICT4D Strategy” OR “ICT4D Implementation methodology" OR "ICT4D Implementation Method" OR "ICT4D Assessment" OR "ICT4D Management". As result, Appendix A shows the papers that have been found and selected in this research per year.

\section{Selection Criteria}

The papers considered in this research are English peer-reviewed studies (conferences proceeding, journal papers and book chapters), relevant studies that focus on ICT4D success and failure factors and which are 
published between 2000 and 2020. Papers excluded from this research are papers that are not written in the English language, are not journal articles, conference proceedings and not book chapters, papers published before 2000 and which are not related to ICT, ICT4D projects,

\section{Research Questions}

The initial research questions were:

RQ1: What are the factors that impact the success of ICT projects?

RQ2: What are the factors that impact particularly the success of ICT4D initiatives?

\section{Results}

This section provides the answers of RQs based on selected primary studies:

RQ1: What are the factors that impact the success of ICT projects?

ICT projects seem to fail worldwide. A vast amount of studies has been done in this discipline. in this section, we will list the common elements between all ICT projects' success and failures identified in pervious works and studies.

Traditionally, the project management triangle or "Iron triangle" has been used to measure project success. Succeed in project management has been linked with the capacity of the project owner to achieve desired outcomes within the defined scope, in time, respecting the estimated cost and the desired level of quality. However, the project owner is challenged and struggling with other constraints than the "measurable scope, cost, time and quality".

As described by (The Standish Group, 2016) a successful project are projects completed on time, within the budgeting cost and who delivered the expected level of client satisfaction. Challenging projects are the ones that exceed the deadline or the fixed budget with less than satisfied customers. A failed project is always canceled or not used by beneficiaries. They also classify projects into two categories: "A winning hand" which is a small and agile project, with a highly agile skilled team, with an executive sponsor and an emotionally mature environment. "A losing hand" represent a large and waterfall project, with poorly skilled teams, with an unskilled and immature sponsor and environment. From this, we can deduce, following the Standish Group, that there are five things to take into consideration to ensure the project success, which are: The project size (small), the project team (skilled and agile), the project management methodology (agile), the sponsor (skilled and committed) and the organization maturity (High level of maturity).

Van Dijk et al. (2013) has analyzed the previous works to establish a chart of Success and Failures Factors in ICT projects (SUFFI). This review has allowed him to identify 139 success and failures factors correlated to ICT projects that have been reduced into 5 elements that he considers the "Most Important Factors (MIFs)" to ICT projects success, which are; (1) poor project management, (2) Deadlines are unrealistic, (3) poor communication, (4) Incomplete/weak requirements definition and (5) Insufficient involvement of future users.

Soltani (2020) Carried out a study to point out the link between business strategy and project strategy and analyzing their impact on the success of ICT projects. This study stated that alignment between business strategy and project strategy has a positive influence on ICT project success and that project development must be part of the enterprise business strategy. A Structural Equation Modelling (SEM) was adopted to check and confirm the proposed result.

A Systematic Literature Review (SLR) of IT project was employed by (Iriarte and Bayona, 2020) that have stated the absence of a consensual definition of project success because of its multidimensional aspect and has shown that IT project success assessment relies on several criteria like context and stakeholder's perception. Following this review, the author was able to group the success criteria identified in the other works and researches into five groups that distinguish between process management success and product management success. Those groups are (1) Project management (Scope definition, Process efficiency, Goals achievement, Project management quality, Stakeholder satisfaction, Team satisfaction) (2) Time and budget (On time, on budget), (3) User satisfaction (end-user satisfaction, intention to use), (4) System quality (System quality, Information quality) and (5) economic value (Business impact, Impact on user).

Delone and McLean (2003) reviewed their definitions of IS success and their related measures and categorized them as follow: (1) System Quality (Access, performance, functionality, etc.), (2) Information quality (Accuracy, Consistency, Relevance, Availability, etc.), (3) Service quality (Training, Flexibility, Responsiveness, etc.), (4) Intention to use/use (Frequency of use, Nature of use, etc.), (5) Effective use/end-user satisfaction and (6) Individual and Organizational benefit.

Other studies performed in the discipline of project management have shown the influence of some factors on project success such as Top management aid and support (Ullah, 2020), Project managers emotional intelligence and leadership competencies (Maqbool et al., 2017), Risk management practices (Pimchangthong and Boonjing, 2017), IT governance practices (Erasmus and Oguntade, 2019), Project sustainability management (Carvalho and Rabechini, 2017), Project planning (Adzmi and Hassan, 2018), Knowledge management processes (Conger, 2013; Yang et al., 2012) and Project Management Office (De Lucca et al., 2020; Pontes, 2020): 
RQ2: What are the factors that impact the especially the success of ICT4D initiatives?

Information and Communication Technology for Development is not a new concept and it plays a key role in international development especially for developed countries. However, many researchers outlined the high rate of failure of ICT4D projects and stated that expectations and objectives are rarely achieved (Chipidza and Leidner, 2017; Venkatesh et al., 2019).

Throughout this section, we will list the ICT4D failure factors pointed out in previous research works. The use of partnership and the multi-stakeholder aspect (public and private institutions and foreign and global players, etc.) of ICT4D projects makes them complex to lead and succeed considering that each stakeholder may have different goals and conditions for the given project. Following to (Kaur et al., 2020), stakeholder's identification, engagement and interaction have an important impact on the fulfillment of ICT4D project goals. Moreover, stakeholder commitment has a critical impact on project sustainability as stated by (Aklilu et al., 2020).

Following the literature review conducted by (Walton and Heeks, 2011) there are five reasons for ICT4D failures: The first reason consists of the lack of users and beneficiaries' involvement in the design phase. ICT4D solutions are often designed by people who do not have a detailed and appropriate comprehension of the context which leads to the design of inappropriate and complex solutions that does not respond to beneficiaries' needs. The second reason is about the lack of addictiveness in the initiative approach delivery, many ICT4D projects establish and stick on a rigid plan and fail to take into consideration flexibility, improvisation and addictiveness through the delivery of the project. Failing to take advantage from errors and experiences constitutes also a reason for ICT4D failures. Research into national and international ICT4D experiences together with trends and best approaches and practices is a foremost building block in the achievement of ICT4D initiatives. Investing time in the research of international experiences and learning from their errors is important and critical to gain an appreciation of the challenges and risks that should be considered in establishing or adapting the planning and outcomes. The fourth reason identified by (Walton and Heeks, 2011) stands for the lack of institutional support, which represents a critical element for the sustainability of ICT4D initiatives. Building or using an existing institution's capacities increases the probability of project success and sustainability. The last but not least reason concerns the presence of an ineffective leadership and governance. Leadership and governance are a necessary part of effective ICT4D projects, they improve transparency, facilitates guidance and ensures that the initiatives are undertaken in a structured, coordinated and timely manner with appropriate stakeholder and workforce consultation.

Besides, (ADHA, 2016) addresses some key success factors that are common to ICT4D projects such as eHealth initiatives. Having an agreed and coherent strategy is a key factor to successfully carry out ICT4D initiatives, as mentioned by the authors, the strategy is critical because it allows a clear representation of the to-be (target) solution, the identification of the strategic outcomes and the setting up of a road map and execution plan to attain the target stage and outcomes while optimizing capabilities and resources and ensuring stakeholder's engagement and investment. They also suggest that the establishment of an effective corporation and collaboration is a crucial factor of success of this type of project given their complex aspect linked to multi-stakeholders and which means that effective communication and collaboration system is a prerequisite to allow quick and effective problem resolution and efficient implementation. Lack of end-user engagement in design and build phases is another key factor of project success because introducing changes in the way people work to take advantage of IT capabilities without taking into account end-users experience and needs can lead to issues in user acceptance and then cause the project failure. Capacity to rapidly iterate, Change management, implementation capability, Measurement, evaluation and benefits management have also been highlighted by the report as key factors success of ICT4D initiatives such as eHealth projects.

In another related work, (Abdulla, 2015) argues that many challenges are facing ICT4D projects implementation such as e-Government projects; among we find challenges associated to strategy, HR skills, systems development methodology, management support, data quality, Business Process Management, Change Management, User Involvement and Organizational Culture and Priority. Furthermore, the author stated that policy and quality management frameworks are foundational prerequisite for the successful implementation of ICT4D initiatives such as e-Government projects.

According to (Dijkers et al., 2018), Agility (collaborative, incremental and iterative approach) can impact positively the ICT4D project success. However, four other criteria must be satisfied before an agile approach can work, namely: ICT4D initiatives must be demand-driven, cultural and organizational context must be analyzed and considered, end-users and trained workforce must to be involved and trust must be built. 
The results of this literature review indicate that consensual about what factors influence the success of ICT/ICT4D projects does not exist. Therefore, various studies and researches have been conducted to establish in which the ICT/ICT4D factors success could be grouped. (Gollner and Baumane-Vitolina, 2016) proposed five categories to group the success criteria of IT projects. This grouping is quite complete since nearly all of the success criteria depicted in this research fit into it. However, other dimensions should be considered while talking about the ICT4D project such as governance, leadership, Legislation, policy, strategy, cultural and organizational context. Considering the categorization proposed by (Gollner and Baumane-Vitolina, 2016), Fig. 1 and Table 1 show the success criteria, latent variables, indicators and the categorization adopted in this article to conduct our analysis.

\section{Conceptual Model}

To identify the factors that affect the success of ICT4D projects, the Partial Least Square Structural Equation Modeling (PLS-SEM) has been used. Fig. 2 presents the conceptual model designed for this aim. SEM is a multivariate method that allows the simultaneous examination of the relationships between the independent latent variables and the dependent latent variables in a model, while multiple regression analysis does not. According to (Ramli et al., 2018) Partial Least Squares is an approach to Structural Equation Models that allows researchers to analyze causal models and latent variables. PLS-SEM approach is used when the analysis is about testing a theoretical framework from a prediction perspective and when the sample size required is smaller than the one used for the other multivariate statistical methods. Besides, PLS-SEM allows testing the statistical significance of the results such as path coefficients, Cronbach's alpha and R square based on the bootstrapping technique. The purpose of this research is to use PLS-SEM to find out the factors influencing the ICT4D project success and detailed the building blocks and process of the proposed development cycle. The suggested model has been evaluated by examining convergent validity, discriminant validity and reliability items. In this study, we, the authors of this study, have assessed the convergent validity and the discriminant validity as recommended by past studies (Caniëls and Bakens, 2012; Soltani, 2020).

Table 1: ICT/ICT4D project success factors and their categories

\begin{tabular}{|c|c|c|}
\hline Factors & Literature review & Times criteria \\
\hline Governance practices & [P8] [P18] [P20] [P22] [P24] & 5 \\
\hline Top management support & [P1] [P12] [P16] [P17] [P18] [P22] [P24] [P29] & 7 \\
\hline Leadership competencies/champions/Sponsorship & [P12] [P18] [P16] [P20] [P22] [P24] & 6 \\
\hline Policy and Legislation & {$[\mathrm{P} 1][\mathrm{P} 22][\mathrm{P} 24]$} & 3 \\
\hline Stakeholders commitment & {$[\mathrm{P} 3][\mathrm{P} 10][\mathrm{P} 20][\mathrm{P} 24]$} & 4 \\
\hline Vision & {$[\mathrm{P} 24][\mathrm{P} 26]$} & 2 \\
\hline Strategy & {$[\mathrm{P} 1][\mathrm{P} 22][\mathrm{P} 24]$} & 3 \\
\hline Cultural and organizational context & [P1] [P7] [P9] [P18] [P22] [P24] [P26] & 7 \\
\hline Risk management practices & {$[\mathrm{P} 13][27]$} & 1 \\
\hline Agility & [P7] [P16] [P18] [P22] & 4 \\
\hline Business and IT alignment & {$[\mathrm{P} 15][\mathrm{P} 20]$} & 2 \\
\hline Knowledge management system/processes & [P18] [P19] [P23] [P24] & 4 \\
\hline Business Process Management & {$[\mathrm{P} 1][\mathrm{P} 6][\mathrm{P} 16][\mathrm{P} 22][\mathrm{P} 24]$} & 5 \\
\hline Communication / collaboration plan & [P6] [P20] [P22] [27] & 3 \\
\hline End-user involvement & [P1] [P6] [P7] [P18] [P22] [P28] & 5 \\
\hline Stakeholders perception & {$[\mathrm{P} 9][\mathrm{P} 10]$} & 2 \\
\hline Stakeholders satisfaction & [P5] [P9] [P10] [P21] & 2 \\
\hline Change management & {$[\mathrm{P} 1][\mathrm{P} 22]$} & 2 \\
\hline Intention to use & {$[\mathrm{P} 5][\mathrm{P} 9][\mathrm{P} 21]$} & 3 \\
\hline User satisfaction & {$[\mathrm{P} 5][\mathrm{P} 9][\mathrm{P} 21]$} & 3 \\
\hline Team satisfaction & [P9] & 1 \\
\hline System use & [P5] [P9] [P21] & 3 \\
\hline System quality & {$[\mathrm{P} 5][\mathrm{P} 9][\mathrm{P} 21]$} & 3 \\
\hline Data / Information quality & {$[\mathrm{P} 1][\mathrm{P} 5][\mathrm{P} 9][\mathrm{P} 21]$} & 4 \\
\hline IT Infrastructure requirements & [P22] [P24] [P26] & 2 \\
\hline Connectivity requirements & {$[\mathrm{P} 22][\mathrm{P} 24][\mathrm{P} 26]$} & 3 \\
\hline Interoperability standards & {$[\mathrm{P} 22][\mathrm{P} 24][\mathrm{P} 26]$} & 3 \\
\hline Security standards & {$[\mathrm{P} 22][\mathrm{P} 24][\mathrm{P} 26]$} & 3 \\
\hline Procedures & {$[\mathrm{P} 22][\mathrm{P} 24][\mathrm{P} 26]$} & 3 \\
\hline Nomenclatures & {$[\mathrm{P} 22][\mathrm{P} 24][\mathrm{P} 26]$} & 3 \\
\hline
\end{tabular}




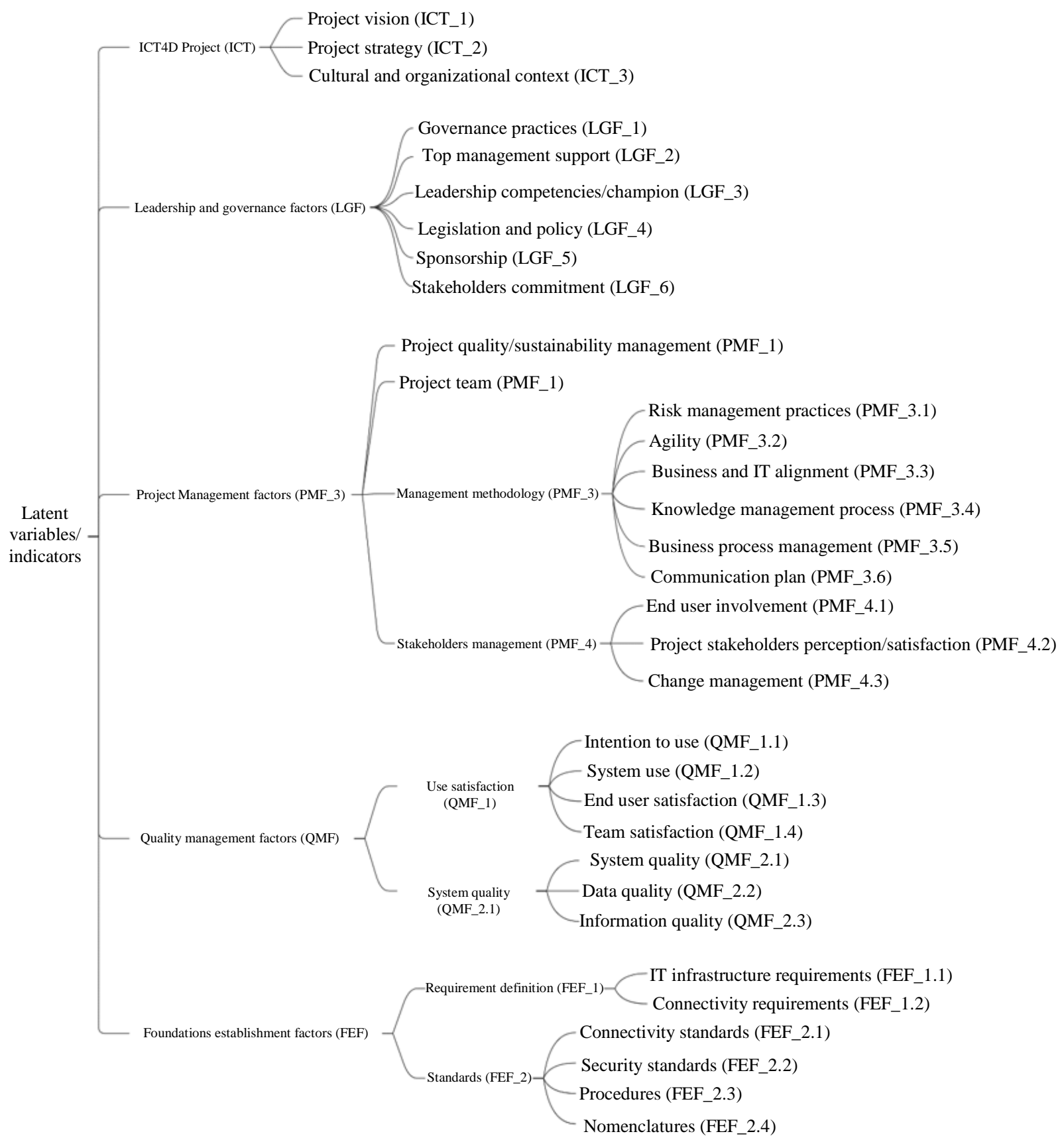

Fig. 1: Latent variables/Indicators

The conceptual model presented in Fig. 2 explains the relationships (Hypothesis) between the exogenous latent variables and endogenous latent variables. To evaluate those hypotheses, the PLS-SEM technique has been used and a model has been designed using a total of 33 indicators which have been depicted from the literature review and organized into five categories as presented in Fig. 1. The five categories are the exogenous latent constructs which are 'Leadership and Governance
Factors' (consist of six indicators: Governance practices, Top management aid and support, Leadership competencies/Champions, Legislation and Policy, Sponsorship and Stakeholder's commitment), 'ICT4D project Factors' (Consist of three indicators: Vision, Strategy and Cultural and Organizational context), 'Project Management Factors' (Consist of four sub-factors categories: Project quality/Sustainability management, Project team, Project Methodology and Stakeholders 
Management), 'Quality Management Factors' (Consist of two sub-factors categories: Use satisfaction and System quality) and 'Foundations Establishment Factors' which Consist of two sub-factors categories: Requirements definition and Standards). The endogenous latent variable is the 'ICT4D Project Success' which is directly correlated to the 'ICT4D project Factors'. Thus, the hypotheses of the present study are as follow:

Hypothesis 1 (H1): Leadership and Governance has a positive and significant effect on ICT4D project success

Hypothesis $2(\mathrm{H} 2)$ : Project Management has a positive and significant effect on ICT4D project success

Hypothesis 3 (H3): Quality Management has a positive and significant effect on ICT4D project success

Hypothesis 4 (H4): Foundations establishment has a positive and significant effect on ICT4D project success

Hypothesis 5 (H5): Leadership and Governance has a positive and significant effect on Foundations establishment

Hypothesis 6 (H6): Project Management has a positive and significant effect on Quality Management

\section{Data Analysis}

\section{Outer Measurement evaluation}

The outer measurement evaluation is the part of the model that calculates the reliability, internal consistency and validity of the latent variables and their indicators (Chin, 1998). To validate the outer measurement models, the authors performed an examination of constructs reliability and validity by evaluating the convergent and the discriminant validity and checking loadings reliability of all indicators to their respective constructs (Urbach and Müller, 2012). Outer loading with 0.70 or greater is believed to be greatly preferred, however, an outer loading with 0.4 or greater is also acceptable according to (Bagozzi and Yi, 1988). From Table 2 we have individual indicators reliability values that are much larger than the minimum acceptable level of 0.4 and much larger than the preferred level of 0.7 (Outer loadings ranged between 0.645 and 0.991). Moreover, Cronbach Alpha and Composite Reliability were utilized to conduct internal consistency evaluation for the construct reliability. From Table 2, such values are highlighted to be larger than 0.70 minimum accepted, a high levels of internal consistency reliability have been demonstrated among all the latent variables. Furthermore, to check convergent validity, Average Variance Extracted (AVE) was evaluated. Table 2 illustrates that all of the AVE values are greater than the acceptable threshold of 0.5 (Bagozzi and Yi, 1988). Thus convergent validity is confirmed.

For discriminant validity, the Fornell-Larcker criterion test and cross-loading have been used. Table 3 shows that the squared root of AVE is larger than the correlation from other latent variables which indicates that discriminant validity is well established. Table 4 shows that indicators are highly correlated to their constructs than any other constructs. Hence, the cross-loading assessment standards are confirmed. As result, the suggested model is supposed to be acceptable with confirmation of convergent validity and discriminant validity.

\section{Structural Model and Hypotheses Testing}

In $\mathrm{H} 1$, we supposed that the leadership and governance would positively and significantly influence ICT4D project success. As predicted, values in Table 5 and Fig. 3 ( $\beta$ coefficient $=0.403$, T-statistic $=6.382$ and $\mathrm{P}$-value $<0.000$ ) confirmed that hypothesis $\mathrm{H} 1$ is robustly supported. likewise, the values in Table 5 and Fig. 3 confirm that the project management factors have a positive influence on ICT4D project success ( $\beta$ coefficient $=0.108$, T-statistic $=7.080$ and P-value <0.000). Hence $\mathrm{H} 2$ is confirmed. The quality management has a significant and positive influence on ICT4D project success $(\beta$ coefficient $=0.265$, T-statistic $=4.820$ and $\mathrm{P}$ value $<0.000)$. Hence $\mathrm{H} 3$ is also robustly supported. Furthermore, values from Table 5 and Fig. 3 show a positive and significant impact of Foundations establishment factors on ICT4D project success $(\beta$ coefficient $=0.581$, T-statistic $=4.890$ and $\mathrm{P}$-value $<0.000)$ and confirmed $\mathrm{H} 4$.

The $\beta$ coefficients enable us to explain how strong the effect of one variable is on another variable and allow us to rank their relative statistical importance (Wong, 2013). Moreover, the greater the $\beta$ coefficient is the stronger influence of the exogenous latent variable on the endogenous latent variable. From Table 5 and Fig. 3 we can conclued that Leadership \& governance (0.403) and Foundations (0.581) have the strongest effect on ICT4D project success, followed by Quality management $(0.265)$ and project management (0.108). Hence the Hypothesis $\mathrm{H} 1, \mathrm{H} 2, \mathrm{H} 3$ et $\mathrm{H} 4$ are statistically significantt because their $\beta$ path coefficients are higher than 0.1 . Thus we reached the conclusion that leadership and governance and Foundations have a moderately strong influence on ICT4D project success, Quality management has a moderate influence on ICT4D project success and Project management is a weak predictor of ICT4D project success. Similarly, Fig. 3 presents that Leadership and Governance has a positive and significant effect on Foundation's establishment $(\beta$ coefficient $=0.548)$ and that Project Management has a positive and significant effect on Quality Management $(\beta$ coefficient $=0.229)$. Hence, H5 and H6 are also supported. 


\section{ICT4D Project Development Approach}

Many developed countries and organizations have proposed documents and toolkits related to the development of ICT4D strategies in different field such as e-Governement (ITU, 2010) and eHealth (ADHA, 2016; Australie, 2008; WHO and ITU, 2014). According to (Scott and Mars, 2013), a few have a simple IT approach to guide the implementation process. (Al-Sharhan et al., 2019; Chipidza and Leidner, 2017; Venkatesh et al., 2019) stated that many ICT4D initiatives are not successful and remain an enduring concern for many countries. In this section, we propose an integrative and structured approach to guide the development and the implementation of ICT4D initiatives, by providing a short description of steps and building blocks that need to be undertaken to develop and implement a sustainable national ICT4D vision.

Fig. 4 presents the ICT4D development and implementation cycle. This cycle will allow stakeholders to ensure a successful, permanent and continual assessment and improvement of the ICT4D vision development and implementation. Figure 5 present the processes of each step. The point of start of this approach consists of the designing of the vision by defining the strategic vision, identifying the business needs and defining architectures (Information, Application and Technology) and the organizational structure. The second step focuses on the gap analysis between the existent state (the as-is) and the desired state (the to-be), the establishment of the ICT4D portfolio, the establishment of priorities and the definition of the transformation plan. The third phase addresses the key IT project concerns, from the reengineering processes to the testing and the validation. The end of the approach cycle concerns the assessment step, this step focuses on the definition of the assessment and monitoring plan, what are the type of KPI and dashboard that should be developed, formulate the gap between what has been designed, planned and what has been executed and establish an action plan to address this gap.

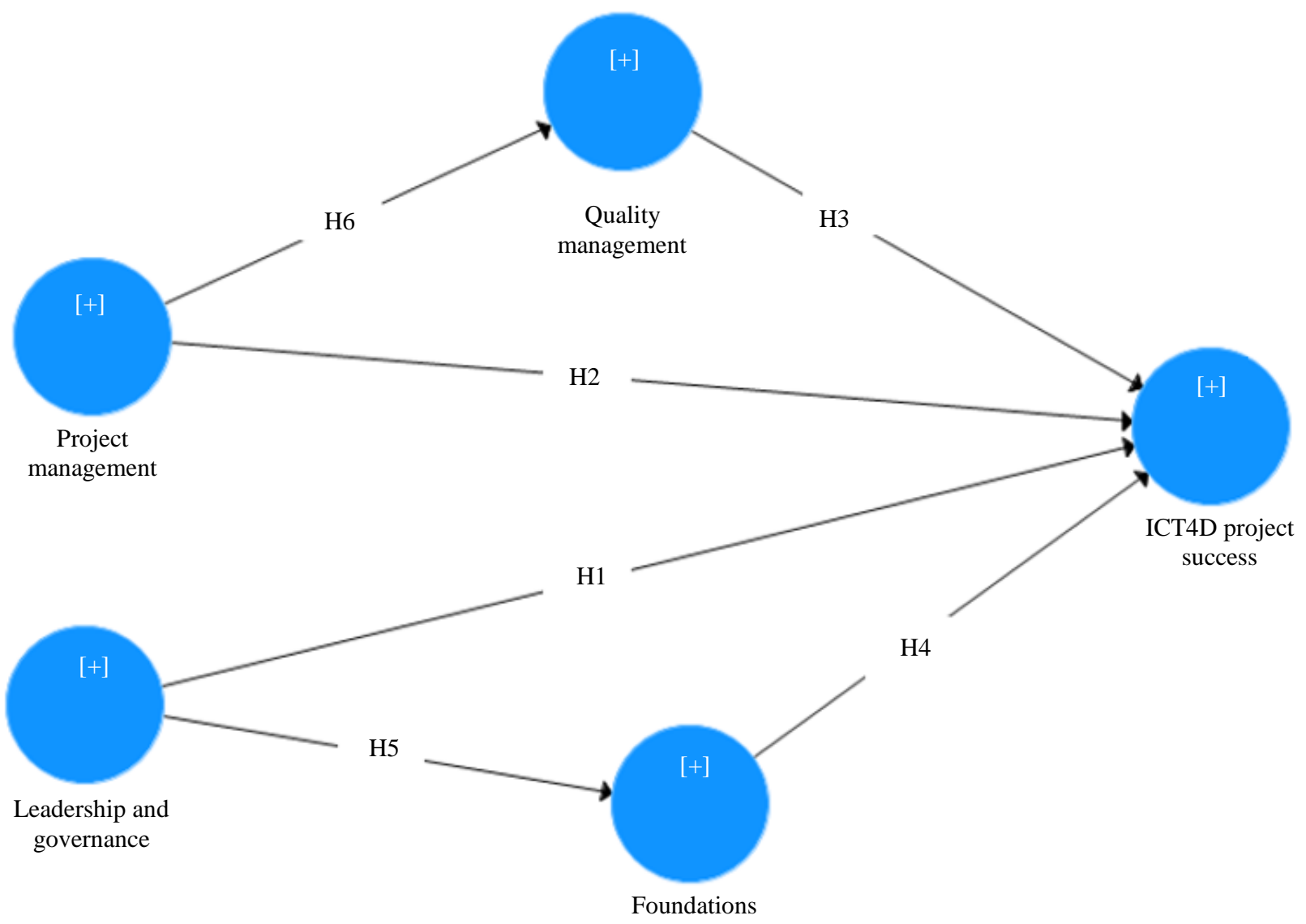

Fig. 2: Conceptual model 


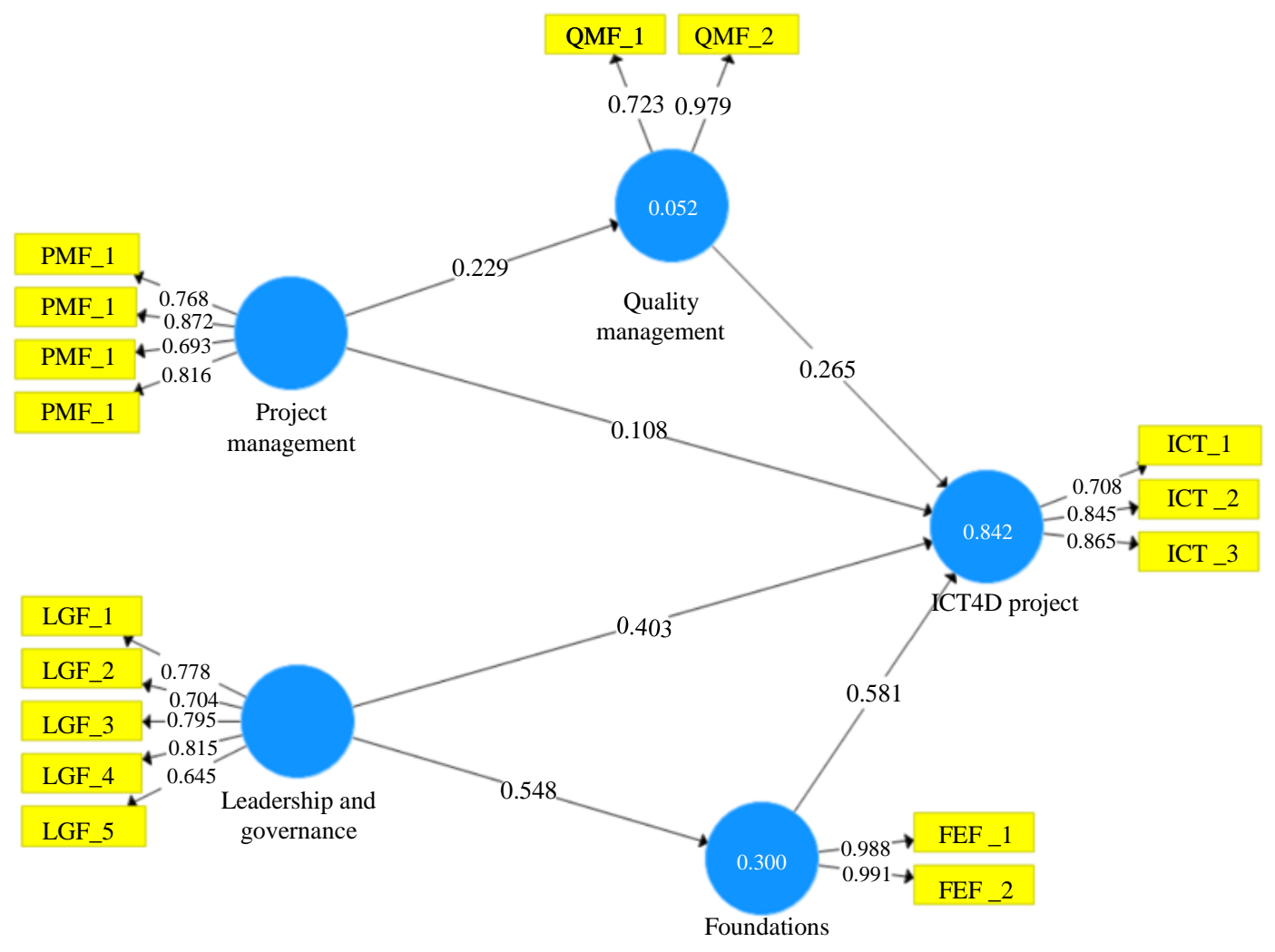

Fig. 3: SEM PLS model

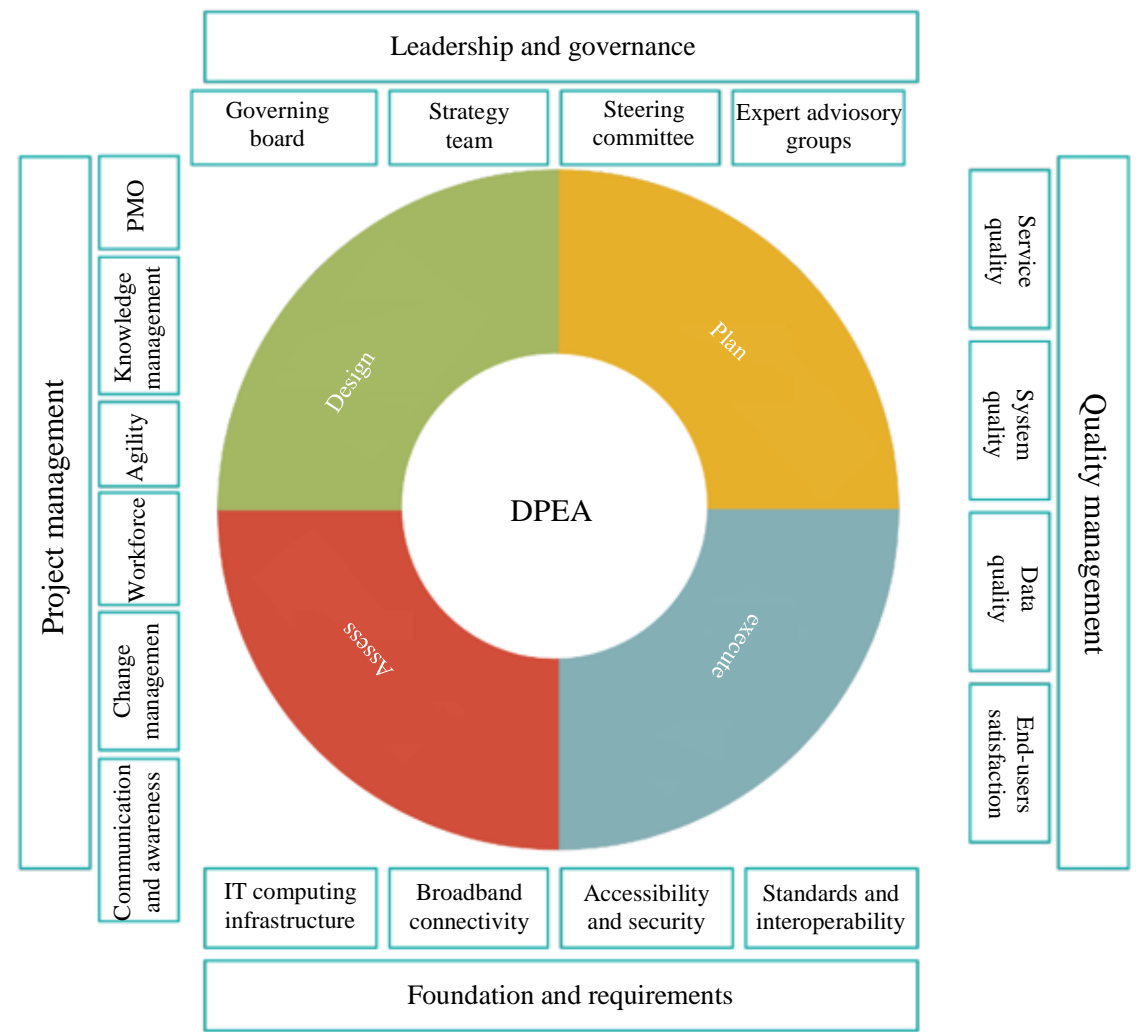

Fig. 4: Design- Plan - Execute - Assess (DPEA) - ICT4D initiatives development cycle 


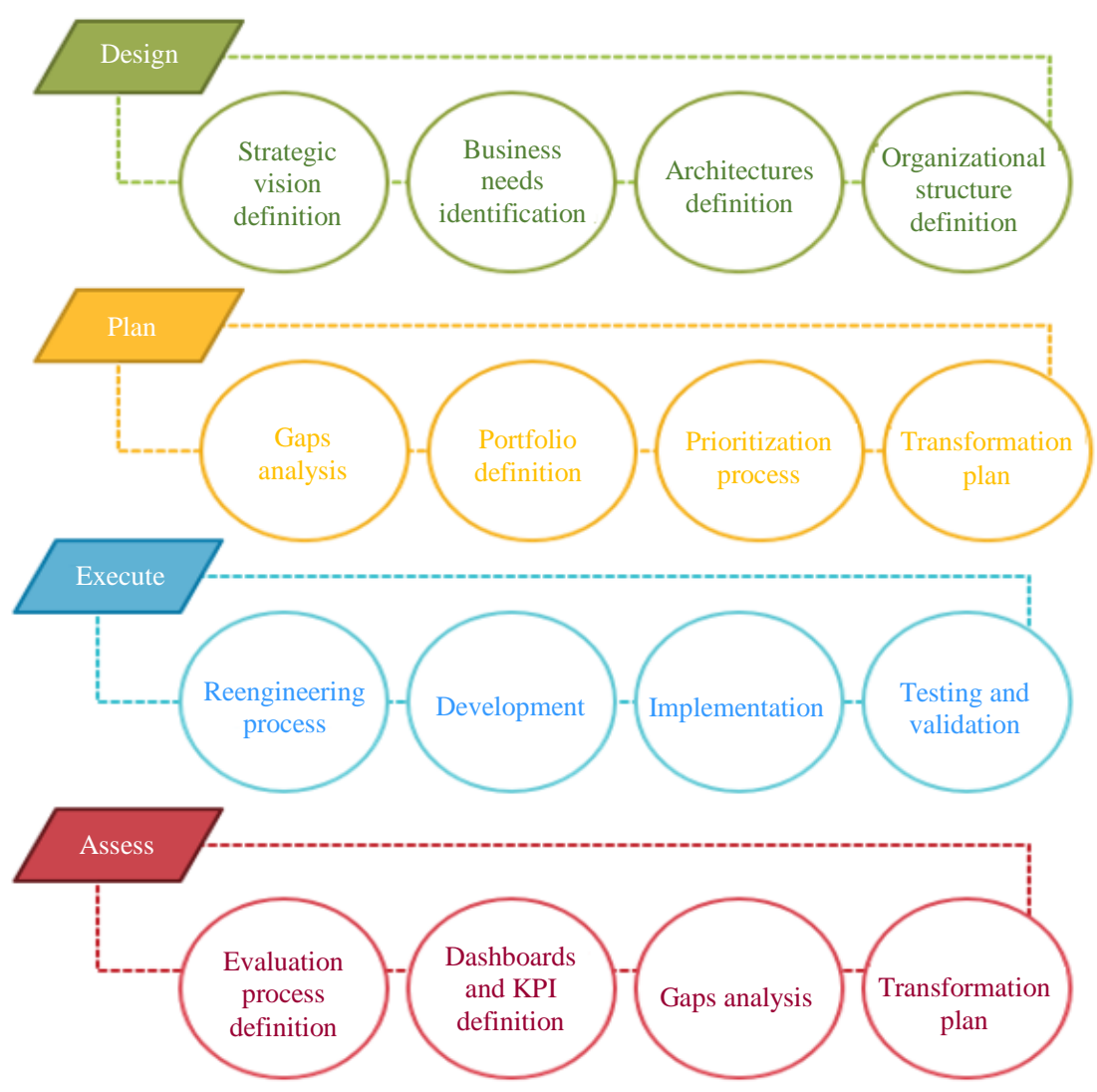

Fig. 5: ICT4D initiatives development approach - Processes

Table 2: Construct reliability and validity

\begin{tabular}{|c|c|c|c|c|c|c|}
\hline Constructs & Factors & Loading & Cronbach alpha & Composite reliability & AVE & R square \\
\hline \multirow{5}{*}{ Leadership \& Governance } & LGF_1 & 0.778 & 0.81 & 0.86 & 0.56 & \\
\hline & LGF 2 & 0.704 & & & & \\
\hline & LGF_3 & 0795 & & & & \\
\hline & LGF_4 & 0.815 & & & & \\
\hline & LGF_5 & 0.645 & & & & \\
\hline \multirow[t]{4}{*}{ Project Management } & PMF_1 & 0.768 & 0.80 & 0.87 & 0.62 & \\
\hline & PMF_2 & 0.872 & & & & \\
\hline & PMF_3 & 0.693 & & & & \\
\hline & PMF_4 & 0.816 & & & & \\
\hline \multirow[t]{2}{*}{ Quality Management } & QMF_1 & 0.723 & 0.92 & 0.85 & 0.74 & 0.03 \\
\hline & QMF_2 & 0.979 & & & & \\
\hline \multirow[t]{2}{*}{ Foundations } & FEF_1 & 0.988 & 0.98 & 0.99 & 0.98 & 0.30 \\
\hline & FEF_2 & 0.991 & & & & \\
\hline \multirow[t]{3}{*}{ ICT4D project success } & $\mathrm{ICT}_{-} 1$ & 0.708 & 0.73 & 0.85 & 0.65 & 0.84 \\
\hline & ICT_2 & 0.845 & & & & \\
\hline & ICT_3 & 0.865 & & & & \\
\hline
\end{tabular}

Table 3: Fornell-Larcker criterion test

\begin{tabular}{llllll}
\hline & LGF & PMF & QMF & FEF & ICT \\
\hline Leadership \& Governance & 0.75 & & & & \\
Project Management & 0.07 & 0.79 & & & \\
Quality Management & 0.03 & 0.23 & 0.86 & 0.99 & \\
Foundations & 0.55 & 0.15 & -0.13 & 0.78 & 0.81 \\
ICT4D project & 0.74 & 0.29 & 0.22 & \\
\hline
\end{tabular}


Table 4: Cross loadings

\begin{tabular}{llllll}
\hline & Leadership and governance & ICT4D project & Project management & Quality management & Foundations \\
\hline LGF_1 & 0.78 & 0.45 & 0.11 & -0.18 & 0.41 \\
LGF_2 & 0.70 & 0.46 & 0.21 & 0.05 & 0.27 \\
LGF_3 & 0.80 & 0.38 & 0.10 & -0.20 & 0.36 \\
LGF_4 & 0.82 & 0.84 & 0.28 & 0.30 & 0.59 \\
LGF_5 & 0.65 & 0.39 & 0.22 & -0.11 & 0.27 \\
ICT_1 & 0.38 & 0.71 & -0.04 & -0.11 & 0.75 \\
ICT_2 & 0.82 & 0.84 & 0.28 & 0.30 & 0.59 \\
ICT_3 & 0.54 & 0.86 & 0.40 & 0.29 & 0.60 \\
PMF_1 & 0.18 & 0.18 & 0.77 & 0.12 & 0.13 \\
PMF_2 & 0.16 & 0.24 & 0.87 & 0.25 & 0.07 \\
PMF_3 & -0.27 & 0.10 & 0.69 & 0.32 & -0.01 \\
PMF_4 & 0.16 & 0.37 & 0.82 & 0.02 & 0.30 \\
QMF_1 & -0.19 & -0.06 & -0.04 & 0.72 & -0.11 \\
QMF_2 & 0.13 & 0.15 & 0.16 & 0.98 & -0.13 \\
FEF_1 & 0.47 & 0.72 & 0.19 & -0.13 & 0.99 \\
FEF_2 & 0.60 & 0.82 & 0.12 & & 0.99 \\
\hline
\end{tabular}

Table 5: Path coefficients and T-Statistics

\begin{tabular}{llll}
\hline Hypothesized path & Standardized beta & T-statistics & P-values \\
\hline Leadership \& Governance -> ICT4D Project success & 0.403 & 6.380 & 0.000 \\
Project Management -> ICT4D Project success & 0.108 & 7.080 & 0.000 \\
Quality Management -> ICT4D Project success & 0.265 & 4.820 & 0.000 \\
Foundations -> ICT4D Project success & 0.581 & 4.890 & 0.000 \\
\hline
\end{tabular}

\section{Conclusion}

This research was conducted to identify the factors affecting the success of ICT4D initiatives and to propose an approach for developing and implementing those latter. For this aim, a literature review was carried out to point out the crucial constructs that impact the ICT4D projects success with their observed variables. Then, a conceptual model was developed and the hypotheses were defined. After that, the Structural Equation Modeling approach was adapted to test and confirm the hypotheses using Smart-PLS 3.3.3.

From the SEM analysis conducted in this study, it is considered that the leadership and governance influence positively and significantly the rate of ICT4D projects' success. Besides, the findings demonstrate that the establishment of foundations and requirements is one of the topmost factors that led to projects' failure. Further, the lack of project management methods increases the rate of ICT4D projects' failure together with the lack of quality management plan, which decreases the projects' quality and leads to their failure. In conclusion, the findings pinpoint that the $\mathrm{R}$ Square value of the model attained 0.84 which refers that the exogenous latent constructs collectively explained $84 \%$ of the ICT4D project success.

This study attempted to ameliorate the expansion of ICT4D research's area by establishing an empirical model and adopting the Structural Equations Modeling (SEM) to check, prove and confirm the hypotheses. The finding of this study will benefit researchers and practitioners intending to understand what the factors and variables that impact the success of ICT4D projects are and put at their disposal a holistic approach to develop and implement ICT4D projects.
The present study is limited by the amount of papers included and analyzed to determine the constructs and their observed variables. To address this limitation, the authors will conduct a pilot study using a questionnaire survey and a focus group interviews to verify, modify, add or delete the variables and constructs reported in this study to validate or update the results of the current study.

\section{Author contribution's}

Houda Fakhkhari: Carried out the research: Conducted the literature review, designed the conceptual model and the framework, applied the SEM approach, analyszed the data and wrote the manuscript in consultation with B.B and M.B.

Bouchaib Bounabat and Maria Bennani: Contributed to the design and implementation of the research, to the analysis of the results and to the writing of the manuscript.

\section{Ethics}

This article is original and contains unpublished material. The corresponding author confirms that all of the other authors have read and approved the manuscript and no ethical issues involved.

\section{References}

Abdulla, M. I. (2015). Challenges of government-togovernment e-government: A case study of KwaZuluNatal department of transport (Doctoral dissertation). https://doi.org/10.14419/ijet.v7i4.35.23078 
Adzmi, R. M., \& Hassan, Z. (2018). A theoretical framework of critical success factors on information technology project management during project planning. http://103.227.140.9/handle/123456789/11593

Aklilu, A., Lessa, L., \& Negash, S. (2020). Understanding the Role of Stakeholders in Fostering Sustainability of ICT4D Projects: Towards a Conceptual Framework.

Al-Sharhan, S., Omran, E., \& Lari, K. (2019). An integrated holistic model for an eHealth system: A national implementation approach and a new cloud-based security model. International Journal of Information Management, 47, 121-130.

doi.org/10.1016/j.ijinfomgt.2018.12.009

ADHA. (2016). "Evolution of EHealth in Australia Achievements, Lessons and Opportunities - Australian Digital Health Agency."

Australie. (2008). "Australie_National EHealth Strategy. Pdf."

Bagozzi, R. P., \& Yi, Y. (1988). On the evaluation of structural equation models. Journal of the academy of marketing science, 16(1), 74-94. doi.org/10.1007/BF02723327

Caniëls, M. C., \& Bakens, R. J. (2012). The effects of Project Management Information Systems on decision making in a multi project environment. International journal of project management, 30(2), 162-175. doi.org/10.1016/j.ijproman.2011.05.005

Carvalho, M. M., \& Rabechini Jr, R. (2017). Can project sustainability management impact project success? An empirical study applying a contingent approach. International Journal of Project Management, 35(6), 1120-1132. doi.org/10.1016/j.ijproman.2017.02.018

Chin, W. W. (1998). The partial least squares approach to structural equation modeling. Modern methods for business research, 295(2), 295-336. https://psycnet.apa.org/record/1998-07269-010

Chipidza, W., \& Leidner, D. (2017). ICT4D research-Literature review and conflict perspective. https://core.ac.uk/download/pdf/301371871.pdf

Comptes, Cour des. 2014. "Rapport de la Cour des comptes sur 1 évaluation des services en ligne."

Comptes, Cour des. 2019. "Rapport de la Cour des comptes sur 1 évaluation des services en ligne."

Conger, S. (2013, October). Knowledge management in LLiSA ICT4D projects. In Proceedings of the South African Institute for Computer Scientists and Information Technologists Conference (pp. 225-232). doi.org/10.1145/2513456.2513464

De Lucca, T. A., Hinnig, M. P. F., \& dos Santos, N. (2020). PMO as a tool for the organizational knowledge management: case study in a project-based company of the sanitation service sector. International Journal of Project Management, 4(1), 10-35.

https://www.ajpojournals.org/journals/index.php/IJP $\mathrm{M} /$ article/view/505
DeLone, W. H., \& McLean, E. R. (2003). The DeLone and McLean model of information systems success: A ten-year update. Journal of management information systems, 19(4), 9-30. doi.org/10.1080/07421222.2003.11045748

Dijkers, J. J. G., Overbeek, S. J., \& España, S. (2018). Improving ICT4D projects with Agile software development. In Proceedings of the 5th International Symposium" Perspectives on ICT4D"(P-ICT4D 2018) co-located with 10th ACM Web Science Conference (WebSci'18), Amsterdam, the Netherlands, May 27, 2018 (Vol. 2120). Sun SITE Central Europe.

Erasmus, W., \& Oguntade, Y. (2019). ICT Governance Practices and Project Success.

Gollner, J. A., \& Baumane-Vitolina, I. (2016). Measurement of ERP-project success: Findings from Germany and Austria. Engineering Economics, 27(5), 498-508. doi.org/10.5755/j01.ee.27.5.13208

Gunawong, P., \& Gao, P. (2017). Understanding e-government failure in the developing country context: a process-oriented study. Information Technology for Development, 23(1), 153-178. doi.org/10.1080/02681102.2016.1269713

Iriarte, C., \& Bayona, S. (2020). IT projects success factors: a literature review. International Journal of Information Systems and Project Management, 8(2), 49-78. https://aisel.aisnet.org/cgi/viewcontent.cgi?article $=1$ $138 \&$ context $=\mathrm{ijispm}$

ITU. (2010). E-Government Implementation Toolkit: E-Government Readiness Assessment Framework. https://www.itu.int/pub/D-STR-GOV.E_GOV-112010

Kaur, R., Ahmed, A., Sargent, J., \& Stockdale, R. (2020). Interactions in ICT4D projects: A sociotechnical perspective. Interactions, 6, 22-2020.

https://researchrepository.griffith.edu.au/bitstream/handle/10072/39 9409/Stockdale440147-Published.pdf?sequence=2

Maqbool, R., Sudong, Y., Manzoor, N., \& Rashid, Y. (2017). The impact of emotional intelligence, project managers' competencies and transformational leadership on project success: An empirical perspective. Project Management Journal, 48(3), 58-75. doi.org/10.1177/875697281704800304

Ministry of Economy. (2019). "Résultats de l'enquête | Indicateurs Globaux : Services Électroniques et Leur Maturité."

Ministry of Industry. (2011). "Programme e-Gouvernement Du Plan Maroc Numeric 2013."

Nations United. (2020). "UN E-Government Survey 2020 - The Digital Government Development."

Pimchangthong, D., \& Boonjing, V. (2017). Effects of risk management practices on IT project success. Management and production engineering review, 8. doi.org/10.1515/mper-2017-0004 
Pontes, D. P. (2020). The IT project management office: a study about its benefits and drawbacks on ICT portuguese sector (Doctoral dissertation). https://run.unl.pt/handle/10362/97600

Qureshi, S. (2019). Perspectives on development: why does studying information and communication technology for development (ICT4D) matter? doi.org/10.1080/02681102.2019.1658478

Ramli, N. A., Latan, H., \& Nartea, G. V. (2018). Why should PLS-SEM be used rather than regression? Evidence from the capital structure perspective. In Partial least squares structural equation modeling (pp. 171-209). Springer, Cham. doi.org/10.1007/978-3-319-716916_6

Scott, R. E., \& Mars, M. (2013). Principles and framework for eHealth strategy development. Journal of medical Internet research, 15(7), e155. doi.org/10.2196/jmir.2250

Seo, D., Tan, C. W., \& Warman, G. (2018). Vendor satisfaction of E-government procurement systems in developing countries: an empirical research in Indonesia. Information Technology for Development, 24(3), 554-581. doi.org/10.1080/02681102.2018.1454878

Soltani, E. (2020). Business and project strategy alignment: ICT project success in Iran. Technology in Society, 63, 101404. doi.org/10.1016/j.techsoc.2020.101404

The Standish Group. (2016). "CHAOS Report 2016 - The Standish Group 2016.”
Ullah, M. S. (2020). "Impact of Entrepreneurial Orientation on Project Success: Mediating Role of Technological Orientation and Moderating Role of Top Management Support.” 131.

Urbach, N., \& Müller, B. (2012). The updated DeLone and McLean model of information systems success. In Information systems theory (pp. 1-18). Springer, New York, NY. doi.org/10.1007/978-1-4419-61082_1

Van Dijk, A. J., White, A. S., \& Comley, R. A. (2013). SUFFI: success and failure factors in ICT projects with Dutch case studies as examples. International Journal of Project Organisation and Management, 5(3), 239-264. doi.org/10.1504/IJPOM.2013.055857

Venkatesh, V., Sykes, T. A., Rai, A., \& Setia, P. (2019). Governance and ICT4D initiative success: A longitudinal field study of ten villages in rural India. MIS Quarterly, 43(4).

Walton, M., \& Heeks, R. (2011). Can a Process Approach Improve ICT4D Project Success?. Development Informatics working paper, (47) doi.org/10.2139/ssrn.3477344

WHO. \& ITU. (2014). "National EHealth Strategy Toolkit."

Wong, K. K. K. (2013). Partial least squares structural equation modeling (PLS-SEM) techniques using SmartPLS. Marketing Bulletin, 24(1), 1-32. file://C:/Users/zonera/Downloads/Smartpls.pdf

Yang, L. R., Chen, J. H., \& Wang, H. W. (2012). Assessing impacts of information technology on project success through knowledge management practice. Automation in construction, 22, 182-191. doi.org/10.1016/j.autcon.2011.06.016

Appendix A: Systematic review selected papers

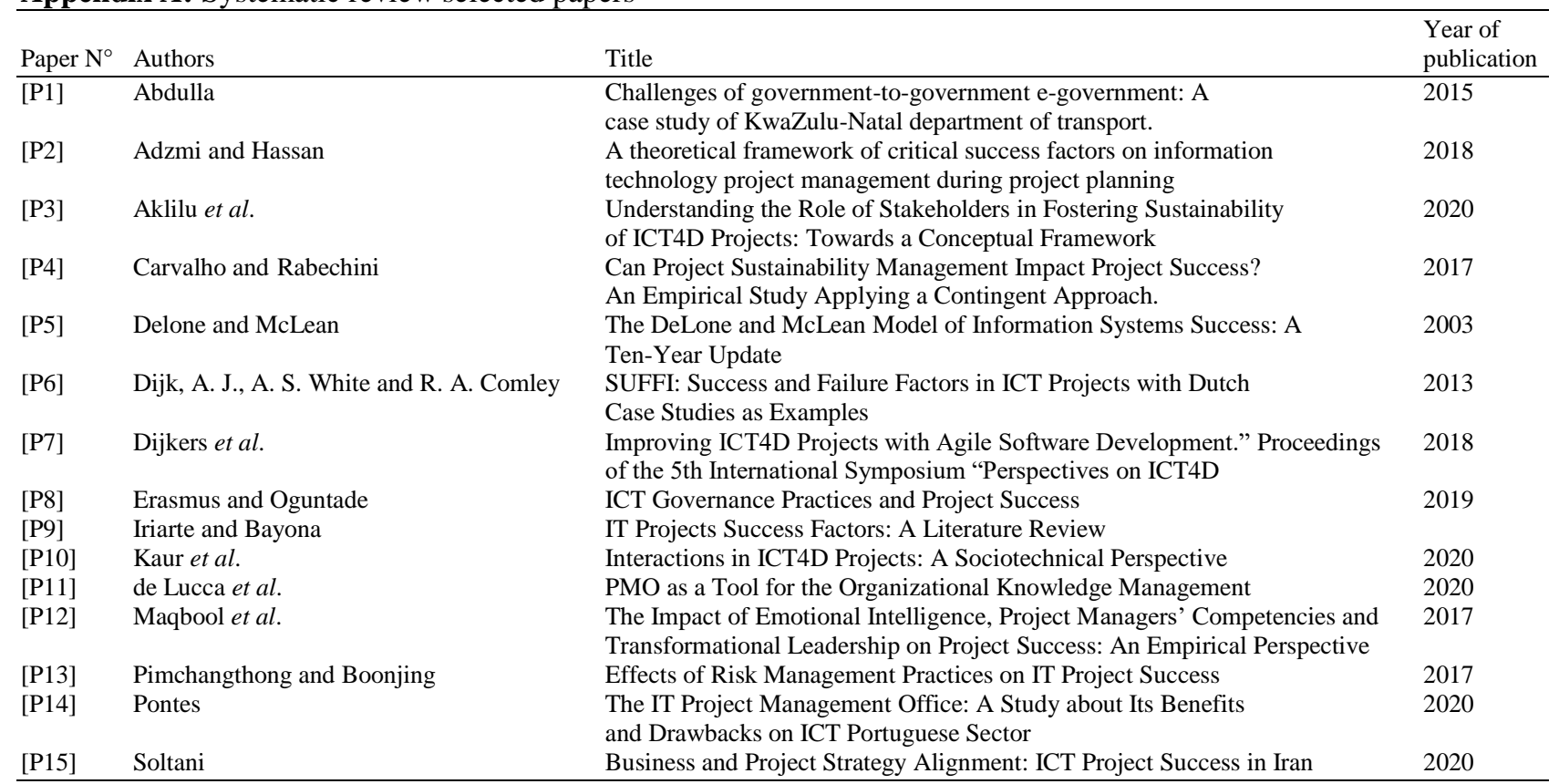


Houda Fakhkhari et al. / Journal of Computer Science 2021, 17 (8): 724.737 DOI: 10.3844/jessp.2021.724.737

Appendix A: Continue

\begin{tabular}{|c|c|c|c|}
\hline$[\mathrm{P} 16]$ & The standish Group & CHAOS Report & 2016 \\
\hline$[\mathrm{P} 17]$ & Ullah & $\begin{array}{l}\text { Impact of Entrepreneurial Orientation on Project Success: Mediating Role of } \\
\text { Technological Orientation and Moderating Role of Top Management Support }\end{array}$ & 2020 \\
\hline$[\mathrm{P} 18]$ & Walton and Heeks & $\begin{array}{l}\text { Can a Process Approach Improve ICT4D Project Success? } \\
\text { Rochester, NY: Social Science Research Network }\end{array}$ & 2011 \\
\hline [P19] & Yang et al. & $\begin{array}{l}\text { Assessing Impacts of Information Technology on Project Success } \\
\text { through Knowledge Management Practice }\end{array}$ & 2012 \\
\hline$[\mathrm{P} 20]$ & $\begin{array}{l}\text { Alaeddini, Morteza, Hamed Asgari, Arash } \\
\text { Gharibi and Mona Rashidi Rad }\end{array}$ & $\begin{array}{l}\text { Leveraging Business-IT Alignment through Enterprise Architecture } \\
\text {-an Empirical Study to Estimate the Extents }\end{array}$ & 2017 \\
\hline [P21] & $\begin{array}{l}\text { Hu, Yong, JingHua Xiao, JiaFeng } \\
\text { Pang and Kang Xie }\end{array}$ & $\begin{array}{l}\text { A Research on the Appraisal Framework of E-Government Project } \\
\text { Success }\end{array}$ & 2005 \\
\hline [P22] & ADHA & $\begin{array}{l}\text { Evolution of EHealth in Australia - Achievements, Lessons } \\
\text { and Opportunities - Australian Digital Health Agency }\end{array}$ & 2016 \\
\hline$[\mathrm{P} 23]$ & Conger, Sue & Knowledge Management in LLiSA ICT4D Projects & 2013 \\
\hline [P24] & WHO, ITU & & \\
\hline [P25] & Gollner and Baumane-Vitolina & Measurement of ERP-Project Success: Findings from Germany and Austria & 2016 \\
\hline$[\mathrm{P} 26]$ & $\begin{array}{l}\text { Fakhkhari, Houda, Bouchaib Bounabat, } \\
\text { Maria Bennani and Rachid Bekkali }\end{array}$ & $\begin{array}{l}\text { Moroccan Patient-Centered Hospital Information System: Global } \\
\text { Architecture }\end{array}$ & 2019 \\
\hline
\end{tabular}

